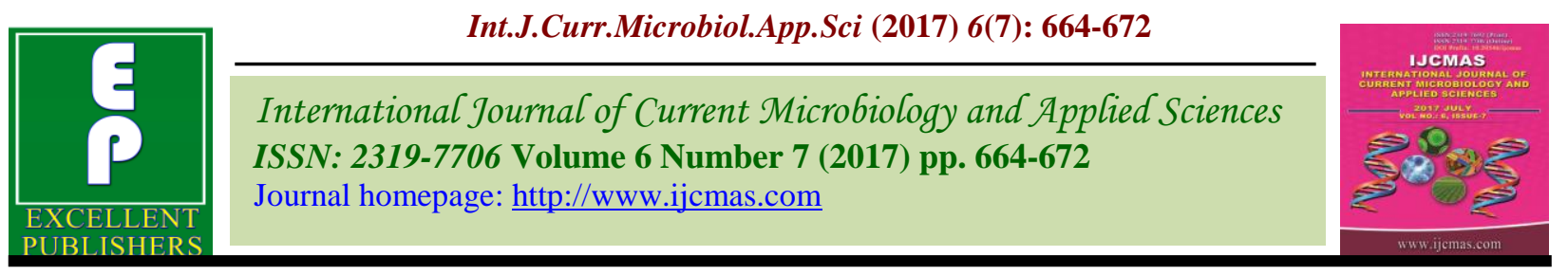

Original Research Article

https://doi.org/10.20546/ijcmas.2017.607.081

\title{
Isolation of Pigmented Yeasts, Extraction of Pigment and Study of Antimicrobial Property of its Pigment
}

\author{
Diksha R. Karanjgaokar* and Kishori S. Tarfe \\ Department of Biotechnology, Smt. Chandibai Himmathmal Mansukhani College, \\ Ulhasnagar, Mumbai, Maharashtra, India \\ *Corresponding author
}

\begin{tabular}{|c|c|}
\hline & A B S T R A C T \\
\hline $\begin{array}{l}\text { Pigmented yeast, } \\
\text { Isolation, } \\
\text { Partitioning, } \\
\text { UV-Visible } \\
\text { spectrophotometer, } \\
\text { Antimicrobial } \\
\text { study. }\end{array}$ & \multirow{3}{*}{$\begin{array}{l}\text { In nature, there exist a wide variety of microbes that can be of any economical } \\
\text { importance to humans. A specialized group of microorganisms includes } \\
\text { pigmented yeasts. They are yeasts that develop colored pigment as their secondary } \\
\text { metabolites. In this study, pigmented yeasts were isolated from different sample } \\
\text { (soil, leaves, fruits, coconut, and air) on Sabouraud's agar. Four strains were } \\
\text { selected that showed pigmentation. Various morphological and biochemical tests } \\
\text { were performed for identification of the strains. The pigments were extracted in } \\
\text { acetone and were partitioned in petroleum ether in separating funnel. The } \\
\text { characterization of the extracted pigments was done using UV-Visible } \\
\text { spectrophotometer. Also the antimicrobial effect of the extracted pigments was } \\
\text { studied against E. coli, S. aureus, K. pneumoniae and } C \text {. diphtheriae. The } \\
\text { pigments extracted from one of the isolate showed increase in antimicrobial } \\
\text { property against K. pneumoniae with increase in volume of pigment. }\end{array}$} \\
\hline Arti & \\
\hline $\begin{array}{l}\text { Accepted: } \\
\text { 14 June } 2017 \\
\text { Available Online: } \\
10 \text { July } 2017\end{array}$ & \\
\hline
\end{tabular}

\section{Introduction}

Yeasts are unicellular, uninucleate eukaryotic fungi that reproduce by forming new cells serially. From the ancient times yeast particularly Saccharomyces cerevisiae are been used in wine or alcohol making industries. In modern sciences their uses are multifaceted such as a) in the production of SCP b) baking industries c) ethanol and acetic acid production d) biocontrol agents against many post harvest vegetable and fruit diseases e) recombinant vaccine production and understanding of cell cycle process and so on (Swapan, 2011). According to Kurtzman and Fell (1998), there exist about 100 genera and
700 species of yeasts (Kurtzman and Fell, 1998). Rhodotorula species are pigmented basidiomycetous yeasts in the family Sporidiobolaceae easily identifiable by distinctive yellow, orange/red colonies (Prabhu et al., 2015; Kaur et al., 2009). Most Rhodotorula species produce colonies that are pink to coral in color but can also be orange to red on Sabouraud's agar.

Most of the natural pigments are extracted from plants like annatto, beet root, marigold, grapes, carrot, paprika, etc. and microorganisms like yeast of the genera 
Phaffia, Rhodotorula, Cryptococcus and Sporobolomyces, fungi like Blakeslea trispora, and algae such as Dunaliella and Haematococcus and bacteria such as Flavobacterium and Micrococcus are reported to produce carotenoids (Manimala et al., 2014). Pigmented yeasts like Rhodotorula and Rhodosporidium produce the major carotenoid pigments viz. carotene, torulene, torularhodin (Kvasnikov et al., 1978). Interest in carotenoids has increased considerably, due in part to the growing evidence of benefits to human health and also to the growth of certain areas of agriculture, especially aquaculture and poultry industry, the utility of carotenoids as anticancer agents, as singlet oxygen or free radical scavengers, as immune response stimulants and as colouring agents for cooked sausage, soft drinks, baked goods and as additive to cosmetics is well known (Amr Abd et al., 2012).

Also, now-a-days antibiotic resistant pathogens pose an enormous threat to the treatment of a wide range of serious infections. To prevent this exponential emergence, a periodic replacement of the existing antibiotic is necessary. Currently, the greatest cause of concern is infection caused by methicillin and vancomycin resistant strains of Staphylococcus aureus, ESBL strains of E. coli, Klebsiella sp., and Pseudomonas aeruginosa. Carotenoids are currently produced for use as nutritional supplements, food colorants, cosmetics or health purposes. Despite the availability of a variety of natural and synthetic carotenoid pigments, there is currently a renewed interest in microbial sources of pigments. There is growing interest in microbial pigments due to their natural character, medicinal properties and nutritive value. Microbial synthesis offers a promising method for production of carotenoids. This explains the increasing interest in production of microbial carotenoids as alternative for synthetic food colorants as well as for using it as antibacterial agent (Manimala et al., 2014).

\section{Materials and Methods}

\section{Isolation of pigmented Yeast from various sources}

The samples which were selected for isolation of pigmented yeasts were soil sample of rose plant and tulsi plant, leaves of tulsi and rose plant, fruits peels of pomegranate, mosambi, coconut shell, dry and wet coconut. Different samples were processed differently for isolation of pigmented yeasts. For isolation of organism from soil sample, the spread plate technique was performed. Dilution upto $10^{-8}$ was prepared using $0.9 \%$ saline. For isolation from leaves, fruit peel and coconut, the surface of sample was directly streaked onto the Sabouraud-Dextrose agar plate with sterile nichrome loop (Yurkov et al., 2008). The inoculated plates were kept for 10 days in order to obtain pigmented yeasts.

\section{Identification of yeast}

For identification of yeast, morphological and biochemical tests were performed. In morphological test, colony characteristics on Sabouraud's agar and microscopic appearance were observed. For microscopic analysis, smear of isolates were Gram's stained and observed under $450 \mathrm{X}$ in compound microscope. In biochemical test, Sugar fermentation test with dextrose, sucrose, mannitol, maltose and lactose as different sugars, nitrate assimilation test and urease test were performed.

\section{Enrichment for carotenoids production}

Yurkov et al., (2008) used enrichment media in order to determine the content of carotenoid pigments from pigmented yeasts (Delia, 1992). So for enrichment of the 
pigments and to check whether the selected yeast strain produces sufficient amount of pigment or not, the selected isolates were

The flasks were kept for six days on a rotary shaker at $260 \mathrm{rpm}$ at room temperature. For taking the absorbance, $\lambda_{\max }$ was determined and that wavelength was selected for taking the absorbance at every 48 hours interval. This helped in selection of those yeast strains that showed higher yield of pigment production.

\section{Extraction of pigment}

The 10 day old yeast cells grown on Sabouraud's agar plate or slants were scraped with nichrome loop and were hydrolyzed with $1 \mathrm{~N} \mathrm{HCl}$ in a water bath at $70{ }^{\circ} \mathrm{C}$ for 15 minutes. The acid free cells were soaked overnight in acetone at $4^{\circ} \mathrm{C}$. The pigment was extracted in acetone and transferred to petroleum ether using a separating funnel and washed thrice with distilled water. The extracted pigments were stored in petroleum ether at $4^{\circ} \mathrm{C}$ (Pfander, 1992).

\section{Characterization of pigment}

For characterization of pigment, its spectrophotometric analysis was performed. The model used for UV-Vis spectrophotometry was Jasco V630 spectrophotometer. Absorbance in both UV and visible range were carried out. The results were obtained using software.

\section{Determination of antimicrobial property of pigment}

The method used for this study was agar cup method/ agar well diffusion method. Bacterial cultures such as E. coli, S. aureus, Klebsiella Pneumoniae, $C$. diphtheriae were selected for testing their susceptibility towards the extracted yeast pigment. These bacterial inoculated in the side arm flask having $20 \mathrm{ml}$ of media. The composition of media is as follows:

\begin{tabular}{|l|l|}
\hline Components & Gms/lit \\
\hline Glucose & 110 \\
\hline Yeast extract & 2.0 \\
\hline Peptone & 1.3 \\
\hline Dipotassium phosphate & 0.2 \\
\hline Monopotassium phosphate & 0.08 \\
\hline Magnesium sulphate & 0.2 \\
\hline Ammonium sulphate & 0.4 \\
\hline Sodium chloride & 0.04 \\
\hline Calcium chloride & 0.02 \\
\hline
\end{tabular}

cultures were suspended in sterile saline to obtain O.D of 0.5 at $545 \mathrm{~nm}$. Mueller Hinton agar (Hi-Media, Mumbai) plates were prepared using the sterilized molten agar medium $0.2 \mathrm{ml}$ of each of above culture suspension was bulk seeded into $20 \mathrm{ml}$ of sterilized molten and cooled Mueller Hinton agar medium.

After solidification, wells were punched by using sterile metal cork borer of internal diameter $10 \mathrm{~mm}$. To the each well, different volumes $(30,50,60,80$, and $100 \mu \mathrm{l} /$ well $)$ of pigments were delivered into them. Control plate was maintained without the addition of carotenoids but petroleum ether alone. All the plates were incubated overnight at $37^{\circ} \mathrm{C}$ under static conditions. After 24 hrs, the antimicrobial activity was evaluated by measuring the diameter of inhibition zone which was expressed in millimeter ( $\mathrm{mm})$.

\section{Results and Discussion}

\section{Isolation of pigmented yeast from various sources}

The soil sample of the rose plant from different places gave 6 different pigmented yeasts whereas tulsi plant gave 3 yeast species. Very few pigmented yeast isolates 
were obtained by streaking surface of fruits peels indicating rare occurrence of pigmented yeast in leaves. Coconut parts were also taken for isolation. Different parts of the plants along with the air sample gave pigmented yeast. Yeasts were also isolated from the air as a contaminant. 18 pigmented yeasts were obtained from 53 different samples.

The coloured colonies were streaked onto Sabouraud's slant and maintained. The 4 isolates were chosen for further analysis as they maintained their pigment colour as well as their growth rate was fast. Table 1 shows the number of sample screened for isolation of pigmented yeast and number of pigmented yeasts obtained.

In the study conducted by Amr Abd ElRhman El-Banna et al., pigmented yeast samples were isolated from different sources like flowers, trees exudates, fruits and cheese. One of which was identified as Rhodotorula var glutinis. Similar studies were conducted by Iriani Maldonade et al., (2007) isolated pigmented yeasts from soil, leaves, fruit, flowers and from processed food.

\section{Identification of yeast}

The 18 yeast isolates were purified and 4 pigmented yeast isolates were selected. The other 14 isolates were ignored because they failed to sustain growth and maintain their colours after subculturing. The further tests were performed for the selected 4 yeast isolates. For identification, colony characteristics, morphological and biochemical tests were performed. The results are shown in table 2 and table 3 . Figure 1 to 4 shows colony characteristics and microscopic observation of the isolates.

Based on the morphological characteristics and biochemical tests we can conclude that the isolated organisms were yeasts.

\section{Enrichment for carotenoids production}

It was observed that isolate no 1 produced more pigments as compared to isolate no 2 , isolate no 3 and isolate no 4 . Isolate no 2 and isolate no. 3 produced in more or less same quantity. Isolate no 4 produced less pigments than all 4 samples. Isolate 1 was found to be high pigments producing strain as compared to the other 3 strains. The results are shown in table 4:

\section{Extraction of pigment (Pfander, 1992)}

The pigments from the yeast isolates were extracted in acetone and partitioned into petroleum ether in a separating funnel. The spectrophotometric results conducted by Latha and Jeevaratnam (2005) revealed that after 90 days of storage, $35 \%$ of the pigments remained stable in petroleum ether kept in dark at $4^{\circ} \mathrm{C}$. Therefore, pigments were kept in dark condition and were stored at $4^{\circ} \mathrm{C}$ under refrigeration condition. These pigments were further used for characterization and for antimicrobial assay. Pigment extracted from isolate no. 1 was labeled as sample 1 and so on.

\section{Characterization of pigment}

For characterization of pigments, the spectra of the carotenoids were analysed at UV-Vis range. For Sample 1, the maximum absorption $\left(\lambda_{\max }\right)$ was observed at $465.5 \mathrm{~nm}$, sample 2 has $450.8 \mathrm{~nm}$ whereas Sample No. 3 and Sample No. 4 had $550.9 \mathrm{~nm}$ and 396.3 $\mathrm{nm}$ respectively. Based on the spectral analysis $\left(\lambda_{\max }\right)$ and the literature available it can be concluded that the pigments of the sample 1 might be $\beta$ - carotene while that of sample 2 might be capsorubin. Sample 3 has far less resembles to any carotenoids in available literature whereas pigment of isolate no 4 i.e. sample 4 resembles $\zeta$ - carotene. The exact characterization of the pigments was not possible as the peaks were merged i.e. it has 
less resolution. The reason for such low resolution is the carbonyl group in conjugation with the series of conjugated bonds extends the chromophore which is the actual reason for shape of spectra and hence it caused bathochromic shift or loss of spectral fine structure, to the extent that the threemaxima spectrum is replaced by a single broad curve. Also the extraction procedure or that pigments being extracted in petroleum ether might also have hindered the spectral line curve (Iriani et al., 2007), Latha and Jeevaratnam (2005) characterized and separated the pigments by column chromatography and purified by thin layer chromatography (TLC). The homogeneity and the purity were checked by HPLC. The structure of carotenoid was determined by taking absorption spectra Shimadzu UV-240 ultraviolet-visible spectrophotometer, nuclear magnetic resonance (NMR) spectroscopy and infrared (FT-IR).

Table.1

\begin{tabular}{|c|c|c|c|}
\hline Sr. No. & Samples processed & No. of samples & No. of pigmented yeast obtained \\
\hline 1. & $\begin{aligned} & \text { Soil sample } \\
& \text { - } \text { Rose plant } \\
& \text { - } \text { Tulsi plant }\end{aligned}$ & $\begin{array}{l}10 \\
10\end{array}$ & $\begin{array}{l}6 \\
3 \\
\end{array}$ \\
\hline 2. & $\begin{aligned} & \text { Leaves of plant } \\
&$\[ \quad \text { Rose plant } \]$ \\
& \text { - } \text { Tulsi plant }\end{aligned}$ & $\begin{array}{l}5 \\
5\end{array}$ & $\begin{array}{l}2 \\
2\end{array}$ \\
\hline 3. & $\begin{array}{l}\text { Fruits peels } \\
\text { - Mosambi } \\
\text { - } \text { Pomegranate }\end{array}$ & $\begin{array}{l}5 \\
5\end{array}$ & $\begin{array}{l}0 \\
1\end{array}$ \\
\hline 4. & $\begin{array}{l}\text { Coconut } \\
\text { • Peels of wet coconut } \\
\text { - Dried coconut } \\
\text { - Wet coconut }\end{array}$ & $\begin{array}{l}3 \\
3 \\
3\end{array}$ & $\begin{array}{l}1 \\
0 \\
1\end{array}$ \\
\hline 5. & Air & 2 & 2 \\
\hline \multicolumn{2}{|c|}{ Total Sample: } & 53 & 18 \\
\hline
\end{tabular}

Table.2 Shows the colony characteristics of the isolated yeasts

\begin{tabular}{|l|l|l|l|l|}
\hline Characteristics & Isolate no 1 & Isolate no 2 & Isolate no 3 & Isolate no 4 \\
\hline Size & $2 \mathrm{~mm}$ & $2 \mathrm{~mm}$ & $3 \mathrm{~mm}$ & $3 \mathrm{~mm}$ \\
\hline Shape & Round & Circular & Round & Round \\
\hline Colour & Orange & Pink & Orange & Orange \\
\hline Appearance & Smooth & Rough & Smooth & Smooth \\
\hline Margin & Entire & Irregular & Entire & Entire \\
\hline Elevation & Raised & Slightly raised & Raised & Raised \\
\hline Gram nature & Positive & Positive & Positive & Positive \\
\hline Cell shape & Oval & Elliptical & Round/oval & Round/Oval \\
\hline
\end{tabular}


Table.3 Results of the biochemical tests of all the four isolates wherein "+" sign indicate positive reaction and "_" sign indicate negative reaction

\begin{tabular}{|c|c|c|c|c|}
\hline Tests & Isolate 1 & Isolate 2 & Isolate 3 & Isolate 4 \\
\hline \multicolumn{5}{|c|}{$\begin{array}{l}\text { 1. Sugar fermentation /gas } \\
\text { production }\end{array}$} \\
\hline - Dextrose & $+1+$ & $+1-$ & $+1-$ & $+1-$ \\
\hline - $\quad$ Sucrose & $+/+$ & $+/-$ & $+/-$ & $+1-$ \\
\hline - Mannitol & $+/+$ & $-1-$ & $-/-$ & $-/-$ \\
\hline - Maltose & $+1+$ & $+1-$ & $+1-$ & $+1-$ \\
\hline - Lactose & $+1+$ & $+/-$ & $+/-$ & $+1-$ \\
\hline 2. Nitrate assimilation & + & - & - & - \\
\hline 3. Urease test & + & - & + & + \\
\hline
\end{tabular}

Table.4 Shows absorbance of the growth of cells in liquid media used for enrichment, at $515 \mathrm{~nm}$ $(\lambda \max )$ at every 48 hours interval

\begin{tabular}{|c|c|c|c|c|}
\hline Organism & $\mathbf{4 8}$ hours. & 96 hours & 144 hours & 192 hours \\
\hline Blank & 0.0 & 0.0 & 0.0 & 0.0 \\
\hline Isolate 1 & 0.94 & 1.54 & 1.64 & 1.29 \\
\hline Isolate 2 & 0.03 & 0.09 & 0.23 & 0.25 \\
\hline Isolate 3 & 0.03 & 0.11 & 0.20 & 0.36 \\
\hline Isolate 4 & 0.02 & 0.06 & 0.10 & 0.10 \\
\hline
\end{tabular}

Table.5 Antimicrobial property of pigments extracted from isolate no. 1 i.e. sample 1

\begin{tabular}{|l|l|l|l|l|l|l|}
\hline \multirow{2}{*}{ Bacterial culture } & \multicolumn{5}{|c|}{ Zone of inhibition (mm) } \\
\cline { 2 - 7 } & Blank (P.E) & $30 \mu \mathrm{l}$ & $50 \mu \mathrm{l}$ & $60 \mu \mathrm{l}$ & $80 \mu \mathrm{l}$ & $100 \mu \mathrm{l}$ \\
\hline E. coli & 0.0 & 0.0 & 0.0 & 0.0 & 0.0 & 0.0 \\
\hline S. aureus & 0.0 & 0.0 & 0.0 & 0.0 & 0.0 & 12 \\
\hline Klebsiella pneumonia & 0.0 & 12 & 14 & 18 & 22 & 26 \\
\hline C.diphtheriae & 0.0 & 0.0 & 0.0 & 0.0 & 0.0 & 0.0 \\
\hline
\end{tabular}

Fig.1

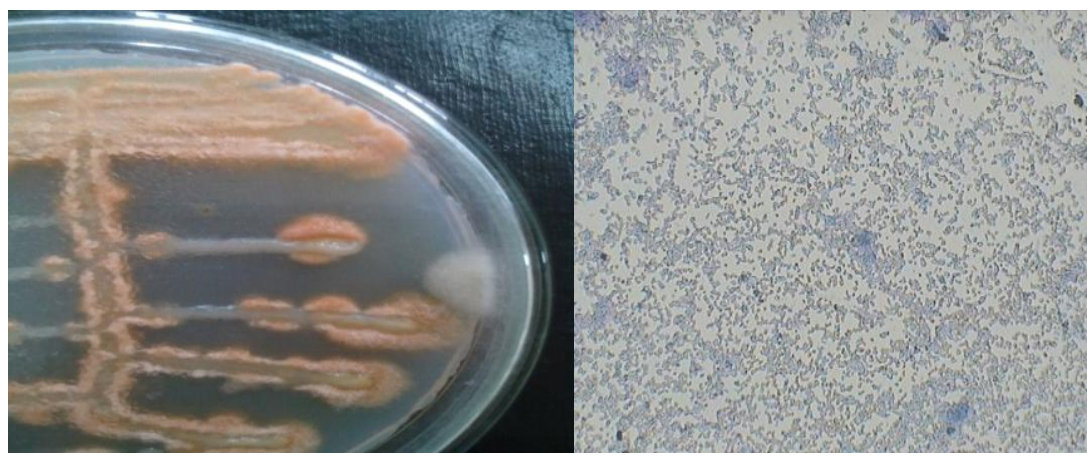


Fig.2

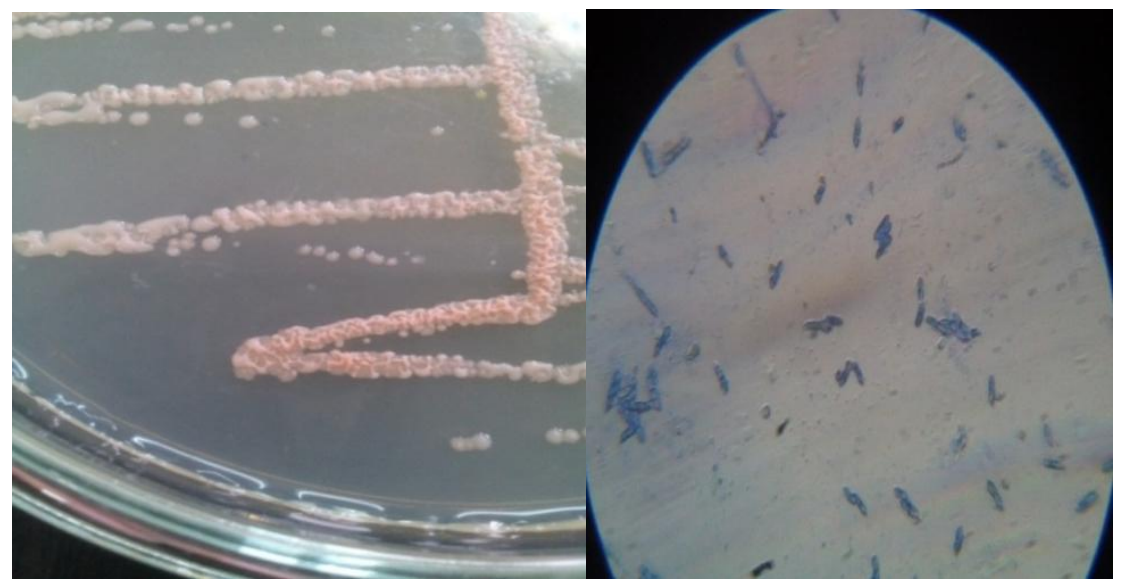

Fig.3

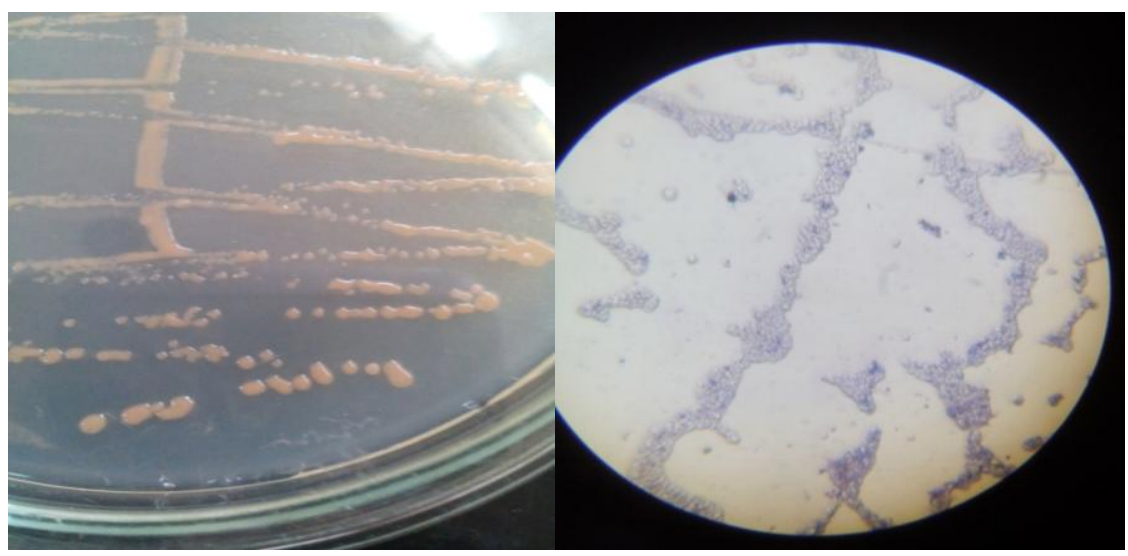

Fig.4

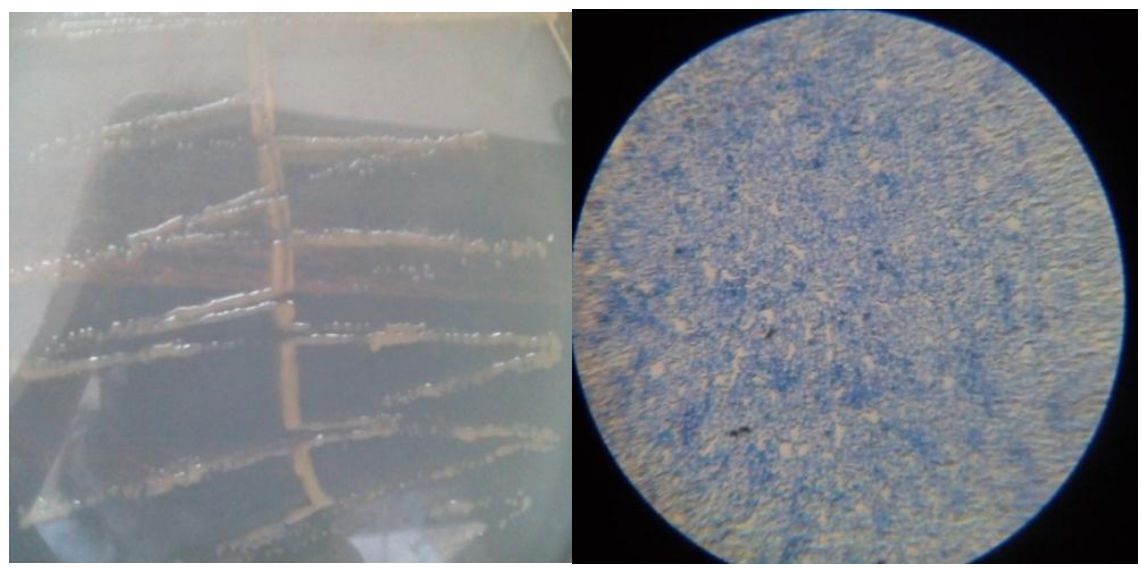


Fig.5

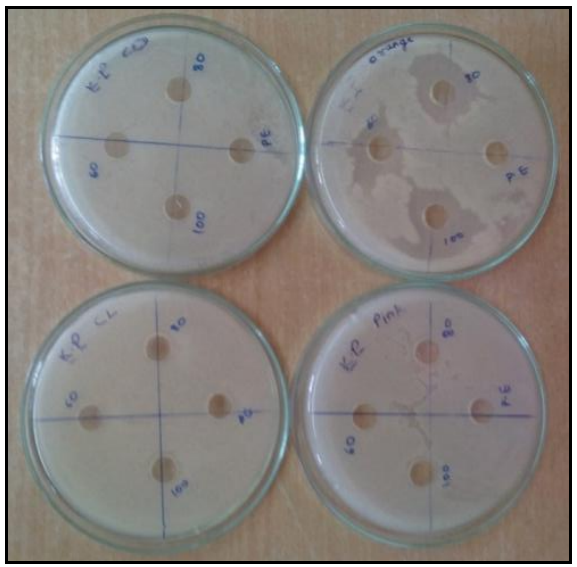

Determination of antimicrobial property of pigment

In order to test the antimicrobial activity of the extracted pigments, agar cup diffusion method was performed. The pigments were added in different volumes to check the antibacterial effect. The bacterial cultures used for the assay were E. coli, S. aureus, Klebsiella pneumoniae, $C$. diphtheriae. Table 5 shows the result for the antimicrobial activity of pigment extracted from isolate no. 1. Figure 5 shows the zone of inhibition by pigment isolated from isolate 1 against Klebsiella pneumoniae.

Rest all of the pigments did not show any antimicrobial effect on any of the bacterial culture. Also there was no growth seen in the blank/ negative control (petroleum ether) suggesting that zone of inhibition was purely by the pigments and not because of any other factor. Patil (2013) evaluated antimicrobial activity of methanolic extract of Punica granatum linn and Cymbopogon against gram positive and gram negative bacteria and obtained good results.

In conclusion, totally 58 samples were processed which included soil of rose and tulsi plant, leaves of rose and tulsi plant, fruit peels, coconut peels and air sample. Out of these, 18 pigmented yeasts were isolated. Out of 18 pigmented yeasts isolated, 4 strains of yeasts were selected as they showed distinct pigment production, faster growth as compared to other isolates and ability to grow on Sabouraud's agar.

Pigmented yeasts were identified on the basis of colony characteristics, morphological and biochemical tests and one isolates (isolate no 1) was found to be Rhodotorula species. Isolate no. 2 , isolate no 3 , isolate no 4 could not be identified just on the basis of these tests.

All the pigments extracted were stored in petroleum ether at $4{ }^{\circ} \mathrm{C}$. The pigment from isolate no 1 i.e., sample 1 was found to be more stable as compared to sample 2, sample 3 and sample 4.

Antimicrobial activity of extracted pigments was tested by agar cup method on organisms such as E. coli, S. aureus, $K$. pneumoniae, $C$. diphtheriae. It was observed that pigment from isolate no 1 which was identified as Rhodotorula spp showed antimicrobial activity against Klebsiella pneumoniae. It could be more interesting to check the antimicrobial activity of the pigments on the isolates obtained from clinical samples. 


\section{References}

Amr Abd El-Rhman El-Banna, Amal Mohamed Abd El-Razek, Ahmed Rafik, El-Mahdy. 2012. Isolation, Identification and Screening of Carotenoid-Producing Strains of Rhodotorula glutinis. Food and Nutrition Sci., 3: 627-633.

Delia, B., Rodriguez-Amaya. 2001. A guide to carotenoid analysis in foods.

Iriani, R., Maldonade, Adilma, R.P. Scamparini, Délia, B., Rodriguez-Amaya. 2007. Selection and characterization of carotenoid-producing yeasts from campinas region, Brazil. Brazilian J. Microbiol., 38: 65-70, ISSN 1517-8283.

Kaur, B., D. Chakraborty, H. Kaur. 2009. Production and stability analysis of yellowish pink pigments from Rhodotorula rubra MTCC 1446. The Internet J. Microbiol., Volume 7 Number 1.

Kurtzman, C.P., J.W. Fell. "The Yeasts, a taxonomic study" Fourth revised and enlarged edition, Elsevier. 1998.

Kvasnikov, E.I., Grinberg, T.A., Vaskivnjnk, V.T., Nagornaja, S.S., Sukenko, V.I. et al. 1978. IZv; ANSS. Yeasts synthesizing carotenoids. $\mathrm{R}$ series Biologicheskja, 4: 565-575.

Latha, B.V. and K. Jeevaratnam. 2010. Purification and Characterization of the Pigments from Rhodotorula glutinis DFRPDY Isolated from Natural Source. Global J. Biotechnol. Biochem., 5(3): 166-174, 2010, ISSN 2078-466X.

Latha, B.V., K. Jeevaratnam, H.S. Murali and K.S. Manja. 2005. Influence of growth factors on carotenoids pigmentation of Rhodotorula glutinis DFR-PDY from natural source Indian J. Biotechnol., Vol 4, pp. 353-357.

Manimala, M.R.A. and R. Murugesan. 2014. "In vitro antioxidant and antimicrobial activity of carotenoid pigment extracted from Sporobolomyces sp. isolated from natural source" J. Appl. Natural Sci., 6(2): $649-653$.

Patil, R.Y., P.N. Jagtap, Lad Meenal, A.C. Sankh, A.V. Patil, O.R. Walwadkar. 2013. "Antimicrobial study of methanolic extract of Punica granatum linn and cymbopogon" J. Biol. Scientific Opinion, Volume 1 930, doi: 10.7897/2321-6328.01311.

Pfander, H. 1992. "Carotenoids: An overview, In: Methods in Enzymology, Carotenoids Part A" Chemistry, Separation, Quantitaion, and Antioxidation volume 213, pp: 3-13 (Ed: Packer, L.). Academic press, San Diego.

Prabhu Prakash, Shashi Verma, Somya Sinha and Seema Surana. 2015. Rhodutorella muciliganes Sole cause of Sacral Abscess in a Neutropenic Child (ALL) after Lumber Puncture - A Case of Hospital Acquired Infection. Int. J. Curr. Microbiol. Appl. Sci., Volume 4 Number 7, pp. 610-616.

Stephen Joseph Gagan. "Characterization of pigments and its slime". University of Tennessee - Knoxville.

Swapan Kr. Ghosh. 2011. Study of yeast flora from fruit of Syzygium cumini (linn) skeel Agri. Biol. J. North America, doi:10.5251/abjna.2011.2.8.1166.1170.

Yurkov, A.M., M.M. Vustin, B.V. Tyaglov, A. Maksimova and S.P. Sineokiy. 2008. Pigmented Basidiomycetous Yeasts Are a Promising Source of Carotenoids and Ubiquinone $\mathrm{Q}_{10}$. Microbiol., Vol. 77, No. 1 , pp. $1-6$.

\section{How to cite this article:}

Diksha R. Karanjgaokar, Kishori S. Tarfe. 2017. Isolation of Pigmented Yeasts, Extraction of Pigment and Study of Antimicrobial Property of its Pigment. Int.J.Curr.Microbiol.App.Sci. 6(7): 664-672. doi: https://doi.org/10.20546/ijcmas.2017.607.081 